\title{
OEANG REPUBLIK INDONESIA PROVINSI SUMATERA (ORIPS) PEMATANG SIANTAR DALAM PERJUANGAN KEMERDEKAAN REPUBLIK INDONESIA DI SUMATERA PADA TAHUN 1947-1949
}

\author{
Sri Utami ${ }^{1}$ \\ Pristi Suhendro Lukitoyo ${ }^{2}$ \\ Fakultas Ilmu Sosial Universitas Negeri Medan \\ Sriutami120697@gmail.com
}

\begin{abstract}
ABSTRAK
Penelitian ini bertujuan untuk mengetahui alasan Provinsi Sumatera mencetak ORIPS, proses pencetakan ORIPS, dan peranannya dalam perjuangan kemerdekaan RI di Sumatera. Metode penelitian yang digunakan dalam penelitian ini adalah metode studi pustaka (library research). Teknik pengumpulan data diambil dari wawancara, observasi dan sumber-sumber buku atau literatur tentang uang. Paska proklamasi kemerdekaan RI kondisi perekonomian Indonesia sangat kacau, diperparah dengan kedatangan tentara NICA yang ingin menguasai wilayah Indonesia kembali. Taktik Belanda untuk menguasai Indonesia dengan menyebarkan uang NICA dan melakukan blokade ekonomi. Untuk mengatasi hal tersebut pemerintah Indonesia membuat kebijakan untuk mencetak uang sendiri. Indonesia menerbitkan uang kertas pertama yang bernama Oeang Republik Indonesia (ORI). ORI hadir untuk menolak uang NICA, uang Jepang, dan Dejavasche Bank yang masih beredar setelah Indonesia merdeka. Dalam peredaran ORI mengalami banyak kendala akibat dari aksi polisionil, blokade dan kondisi geografis sehingga uang ORI tidak tersebar merata ke seluruh daerah termasuk Pulau Sumatera. Agar kegiatan perekonomian tetap berjalan melalui peraturan pemerintah No. 19/1947 tertanggal 26 Oktober 1947 Pemerintah memberikan wewenang kepada pemerintah Daerah tingkat Provinsi untuk mencetak uang daerah (ORIDA). Provinsi Sumatera mencetak uang bernama ORIPS yang terbit pada 11 April 1947 di Pematang Siantar. ORIPS terdiri dari pecahan 1, 5, 10, dan 100 roepiah. Bahan kertas yang digunakan adalah kertas HVS. Proses pencetakan ORIPS dilaksanakan di Percetakan Negara II (Percetakan Deli) yang sebelumnya telah dipidahkan dari Kota Medan ke Kota Pematang Siantar. ORIPS menjalankan peranannya sebagai alat perjuangan karena dapat membiayai segala keperluan negara yang baru berdiri, Seperti membiayai gaji pegawai, polisi, tentara, dan menanggulangi perekonomian rakyat .
\end{abstract}

Kata Kunci : Ekonomi, ORIPS, Perjuangan 


\section{PENDAHULUAN}

Pentingnya keberadaan uang sebagai alat perjuangan menegakkan kedaulatan ekonomi dan mempertahankan kemerdekaan Indonesia memainkan peran yang tidak kalah hebatnya. Uang dalam hal ini tidak hanya berfungsi sebagai alat tukar dan simbol sebuah negara yang berdaulat, namun lebih dari pada itu, uang juga merupakan senjata dalam menghadapi serangan ekonomi yang dilancarkan oleh Belanda kepada Indonesia (Darsono dkk, 2017:206). Uang tersebut dijadikan sebagai alat perjuangan karena merupakan atribut kemerdekaan bangsa dan langkah awal sistem keuangan Indonesia.

Paska proklamasi kemerdekaan Republik Indonesia keadaan ekonomi moneter di Indonesia masih sangat kacau. Hal ini ditandai dengan masih beredarnya uang kertas pendudukan Jepang di kalangan masyarakat dan dinyatakan sebagai alat pembayaran yang sah di Indonesia yang diperkirakan sejumlah 4 milyar rupiah. Pemerintah RI menyadari bahwa belum mampu untuk mengeluarkan mata uangnya sendiri, maka melalui Maklumat Presiden RI no. 1/10, tanggal 3 Oktober 1945, menetapkan untuk sementara waktu masih berlaku tiga jenis mata uang diseluruh wilayah Republik Indonesia yaitu: pertama uang De Javasce Bank, kedua uang Hindia Belanda, ketiga uang Pendudukan Jepang (Soedarjdo, 1991:2-4). Akibat uang Jepang yang masih beredar di wilayah Indonesia itu menjadi salah satu faktor kekacauan ekonomi yang harus ditanggulangi oleh Pemerintah Republik Indonesia pada saat itu.

Uang Republik Indonesia (ORI) adalah uang kertas pertama yang dikeluarkan oleh pemerintah Republik Indonesia. Dikeluarkannya uang ini bertujuan untuk mengatasi inflasi karena banyaknya mata uang Jepang dan mata uang Hindia Belanda yang masih beredar di masyarakat dan masih berlaku sebagai alat pembayaran yang sah pada saat Indonesia baru merdeka. Selain untuk mengatasi inflasi uang ini juga bertujuan untuk legitimasi kedaulatan Republik Indonesia. Setelah dikeluarkannya ORI ternyata tidak membuat kondisi ekonomi keuangan Republik Indonesia membaik, hal ini dikarenakan peredaran ORI mengalami banyak kendala karena pendudukan Belanda yang ingin kembali menguasai Indonesia tidak tinggal diam, Belanda berusaha membuat perekonomian 
Republik semakin terpuruk, dan Belanda juga melemahkan perekonomian Indonesia dengan mengeluarkan ORI palsu. Selain kondisi keamanan yang kurang mendukung, dan pemalsuan uang ORI oleh NICA membuat pengedaran ORI di tahap awal sangat sulit dan tidak berlangsung sesuai target yang diharapkan (Darsono dkk, 2017:240-243).

Setelah ORI beredar di wilayah Jawa dan Madura, peredaran ORI di Sumatera tidak dapat terlaksana dengan baik. Belanda telah melakukan blokade ekonomi dengan menguasai pelabuhan-pelabuhan penting di Sumatera. Pemerintah Indonesia kemudian mengeluarkan kebijakan bahwa untuk daerah di luar Pulau Jawa dan Madura, untuk sementara tetap menggunakan uang Jepang. Namun seiring berjalannya waktu pengiriman ORI ke Pulau Sumatera tidak dapat terealisasikan karena Agresi militer Belanda I pada tahun 1947 mempersulit keadaan dan tidak memungkinkan untuk pelaksanaan pengiriman ORI (Darsono dkk, 2017: 243-244). Oleh karena itu, pemerintah mengambil langkah agar kebutuhan dan perekonomian tiap-tiap daerah tidak terhambat, maka melalui Peraturan Pemerintah No. 19/1947 tertanggal 26 Oktober 1947 Pemerintah Daerah tingkat Provinsi, Keresidenan, dan Kabupaten diberikan wewenang untuk menerbitkan Oeang Republik Indonesia Daerah (ORIDA). ORIDA adalah uang kertas atau tanda pembayaran yang sah yang berlaku secara terbatas didaerah tersebut, (Darsono dkk, 2017:248).

Oeang Republik Indonesia Provinsi Sumatera (ORIPS) adalah ORIDA pertama di Pulau Sumatera yang diterbitkan di Pematang Siantar oleh percetakan Deli yang sebelumnya telah dipindahkan dari Berastagi ke Kota Pematang Siantar. Uang ini diterbitkan di Pematang Siantar karena ibu kota provinsi Sumatera pindah dari Medan ke Pematang Siantar, kondisi keamanan di Medan sudah tidak aman karena Belanda dan Tentara sekutu telah mendarat di Belawan dan menduduki kota Medan. 


\section{METODE DAN FOKUS PENELITIAN}

Metode yang digunakan oleh penulis dalam penelitian ini adalah Studi Lapangan (Field Research) dan Studi Pustaka (Library Research) dan sumber lain guna memperoleh data. Penelitian ini dilakukan di Museum Uang Sumatera (MUS) JL. Pemuda, No 17, A U R, Medan Maimun, Kota Medan. Adapun sumber data yang digunakan dalam penelitian ini adalah sumber primer dan sumber sekunder.

\section{HASIL DAN PEMBAHASAN}

\section{Kondisi Ekonomi Sumatera Paska Proklamasi Kemerdekaan}

Di Sumatera kondisi ekonomi sangat memprihatinkan, ditandai dengan kemuduran produksi pertanian, pertambangan, serta terganggunya perdagangan. Pada pendudukan Jepang, hasil- hasil pertanian seperti beras dibeli dengan harga yang sangat murah oleh pemerintah militer Jepang, Akibatnya para petani tidak bergiat dalam menjalankan pertanianya.

Ratusan hektar lahan perkebunan dan pertanian rakyat rusak berat selama masa perang dan pendudukan Jepang di Sumatera Timur. Hal ini berdampak langsung pada kemunduran produksi tanaman ekspor. Kehancuran juga terjadi pada ratusan instalasi pabrik dan berbagai industri strategis lainnya yang menjadi tumpuan perekonomian. Perang yang terjadi tidak hanya memakan korban jiwa, namun juga memporak-porandakan perekonomian bangsa. (Darsono dkk,2017:239).

Pemerintah RI di Sumatera terus berupaya memperbaiki perekonomian di daerahnya, sebagai langkah pertama, pemerintah Republik mulai mengatur peredaran bahan makanan dengan membentuk Ekonomi Rakyat Republik Indonesia (ERRI) di Kota Medan. Badan ini bertugas mengawasi seluruh barangbarang yang masuk ke Kota Medan.

Upaya-upaya yang dilakukan pemerintah Provinsi Sumatera dalam memperbaiki perekonomian ternyata belum memberi pengaruh signifikan. Kondisi perekonomian Sumatera semakin sulit akibat peredaran uang pendudukan Jepang yang sangat banyak (kira-kira 2 miliar) yang mengakibatkan nilai uang tersebut 
sangat rendah (inflasi). Pemerintah Republik di Sumatera tidak dapat mengatasi masalah keuangan karena secara resmi sampai tahun 1946 belum memiliki mata uang sendiri. Harga barang-barang di pasaran terus melambung tinggi akibat peredaran uang Jepang yang terus meningkat.

Keadaan itu tentu saja mengakibatkan kekacauan ekonomi yang mengganggu kehidupan masyarakat dan jalannya Pemerintahan Repulik Indonesia di Sumatera. Masyarakat semakin menderita akibat kesulitan dalam memperoleh bahan makanan karena harganya yang terus melambung di tengah munculnya berbagai jenis mata uang yang berlaku. Peredaran berbagai jenis mata uang pendudukan Jepang di Indonesia memicu inflasi besar-besaran dan juga telah mempengaruhi Kas Negara Indonesia pada masa awal kemerdekaan yang berasal dari Fonds Kemerdekaan Indonesia (FKI). Untuk mengatasi hal tersebut pemerintah Republik Indonesia memandang perlu untuk mencetak mata uang sendiri. Uang ini bagi Republik Indonesia tidak sekedar sebagai alat pembayaran semata-mata tetapi juga berfungsi sebagai lambang utama bagi suatu negara merdeka dan sebagai alat perjuangan di dunia internasional. Upaya pencetakan uang kemudian menjadi perhatian serius bagi pemerintah untuk menghadapi kekacauan ekonomi.

\section{Upaya Pencetakan Oeang Republik Indonesia (ORI)}

Menjelang akhir Oktober 1946 kerja besar dan kerja keras pemerintah untuk menerbitkan uang sendiri akhirnya membuahkan hasil. Undang-Undang Nomor 17 Tahun 1946 tanggal 1 Oktober 1946 menetapkan penerbitan Oeang Republik Indonesia.Berdasarkan Keputusan Menteri Keuangan No.SS/35 tanggal 29 Oktober 1946 ditetapkan berlakunya ORI secara sah yang mulai berlaku sejak tanggal 30 Oktober 1946 pukul 00.00. Perlu di sampaikan ORI yang pertama kali di edarkan adalah ORI yang diproduksi di Jakarta pada bulan Oktober 1945.

Setelah ORI beredar di wilayah Jawa dan Madura, peredaran ORI di pulau Sumatera tidak dapat terlaksana dengan baik. NICA telah melakukan blokade ekonomi dengan menguasai pelabuhan-pelabuhan penting di Sumatera. Pengiriman ORI yang dilaksanakan lewat jalur laut pun terkendala keamanan sehingga 
Pemerintah Indonesia kemudian mengeluarkan kebijakan bahwa untuk daerah di luar Pulau Jawa dan Madura, untuk sementara tetap menggunakan uang Jepang. Namun seiring berjalannya waktu pengiriman ORI ke Pulau Sumatera tidak dapat terealisasikan karena Agresi militer Belanda I pada tahun 1947 mempersulit keadaan dan tidak memungkinkan untuk pelaksanaan pengiriman ORI. Di lain sisi, kebutuhan keuangan di Sumatera terus meningkat seiring dengan upaya mempertahankan kemerdekaan Indonesia di Sumatera serta untuk kebutuhan pendaanaan pemerintahan daerah. (Darsono dkk, 2017:243-244).

\section{Latar Belakang dan Proses Pencetakan ORIPS di Pematang Siantar}

Kesulitan keuangan mengakibatkan pemerintahan di Provinsi Sumatera menjadi terganggu, terutama untuk memenuhi kebutuhan perang melawan pasukan Sekutu dan Belanda yang membutuhkan dana tidak sedikit. Oleh karena itu, pemerintah mengambil langkah agar kebutuhan dan perekonomian tiap-tiap daerah tidak terhambat, melalui peraturan pemerintah no.19/1947 tertanggal 26 Oktober 1947 pemerintah daerah tingkat provinsi, keresidenan, dan kabupaten diberikan wewenang untuk menerbitkan Oeang Republik Indonesia Daerah (ORIDA). ORIDA merupakan uang kertas atau alat pembayaran yang sah yang berlaku secara terbatas di daerah tersebut.

Sebelum adanya peraturan pemerintah mengenai wewenang setiap daerah boleh mencetak uang sendiri, Teuku Muhammad Hasan selaku Gubernur Sumatera dan Wakil Pemerintah pusat di Sumatera meminta pertimbangan Mentri Keuangan, Mr Syafrudin Prawiranegara agar pemerintah Provinsi Sumatera dapat mencetak uang sendiri. Syafrudin merespon permintaan tersebut kemudian memberikan usul agar Sumatera mencetak Promesse "Surat Janji” namun Hasan memiliki pandangan lain. Menurutnya uang kertas akan jauh lebih efektif daripada promesse. Setelah melakukan berbagai diskusi yang panjang, akhirnya Teuku Muhammad Hasan memutuskan untuk mencetak uang ORIPS (Oeang Republik Indonesia Provinsi Sumatera).

Sebagai langkah pertama dalam upaya mencetak ORIPS, Gubernur Sumatera T.M. Hasan memberlakukan Maklumat No. 92/KO pada tanggal 8 April 1947 
tentang mengeluarkan uang/tanda pembayaran resmi di Sumatera. ORIPS di terbitkan di Pematang Siantar pada 11 April 1947. Dalam maklumat tersebut ditetapkan bahwa ORIPS berlaku di seluruh dan sebagian wilayah Sumatera sebagai alat pembayaran yang sah. ORIPS emisi Pematang Siantar ini dijamin oleh pemerintah pusat RI dan dapat ditukar dengan ORI dengan nilai tukar 1:1. (Darsono dkk, 2017:248).

Pencetakan ORIPS selanjutnya dilaksanakan di Percetakan Negara II (Percetakan Deli) yang sebelumnya telah dipidahkan dari Kota Medan ke Kota Pematang Siantar. Percetakan ini telah banyak membantu Pemerintah Sumatera dalam bidang cetak-mencetak. ORIPS yang bertanggal 31 Maret 1947 itu baru dapat dicetak pada bulan April 1947, adapun jenis pecahan yang dicetak adalah pecahan 1 Rupiah, 5 Rupiah, 10 Rupiah, dan 100 Rupiah. ORIPS ditandatangani oleh R.A. Herman dan R.M. Amin, sedangkan harga satu Rupiah ORIPS sama dengan satu Rupiah ORI dan seratus Rupiah uang Jepang. Untuk pengaman dari pemalsuan uang ORIPS emisi Pematang Siantar menggunakan Kode Kontrol. Masing-masing nilai uang memiliki warna yang berbeda, ada yang memakai warna biru dan hijau. Untuk sisi depan uang terdapat lukisan gambar Soekarno, gunung, aktivitas petani di sawah dan nilai uang. Gambar Soekarno yang dicantumkan pada berbagai jenis ORI dan ORIDA yang pernah diterbitkan pada masa revolusi kemerdekaan merupakan simbol semangat dan pemersatu rakyat Indonesia dalam memperjuangkan kemerdekaan. Sementara itu dibagian belakang adalah gambar ornamen dan nilai uang.

ORIPS mulai diedarkan di sumatera pada tanggal 11 April 1947 sebagai tanda pembayaran yang khusus berlaku di daerah Sumatera saja. Berdasarkan maklumat gubernur Sumatera no 92/K.O tertanggal 8 april 1947. Uang ini dijamin pemerintah RI dan dapat ditukar dengan Uang Republik Indonesia (ORI) dengan nilai 1:1, sedangkan ORIPS dengan uang jepang 1:100. Peredaran ORIPS tidak dapat berjalan lancar karena adanya blokade oleh Belanda kemudian Belanda juga melakukan berbagai pengawasan-pengawasan sehingga sulitnya untuk mendistribusikan uang tersebut. Uang ORIPS yang akan di sebarkan ke Daerah- 
daerah sebelumnya akan di beri cap stempel dan label sesuai dengan daerahnya masing-masing.

Agresi Militer Belanda I pada tanggal 21 juli 1947 kota Pematang Siantar di serbu oleh Belanda. Akibatnya seluruh mesin pencetak ORIPS jatuh di tangan Belanda Sehingga Percetakan ORIPS terhenti. Kemudian mesin cetak yang berhasil di rebut Belanda kemudian dimanfaatkan Belanda untuk memalsukan uang ORIPS yang bertujuan untuk mengacaukan perekoniman rakyat. Uang palsu tersebut tersebar ke daerah Tapanuli, Aceh hingga Sumatera Barat. Keadaan semakin kacau ketika komplotan pemalsu uang dari Singapura turut ambil bagian besar dalam memalsukan ORIPS tersebut. Pemerintah segera melakukan kebijakan pembersihan dan pemberitahuan kepada masyarakat akan keberadaan uang palsu.

\section{Pencetakan ORIPS di Bukit Tinggi}

Setelah Belanda melacarkan agresi militer I dan menduduki kota Pematang Siantar. Akibat agresi ini, Unit Percetakan Negara II seluruhnya jatuh ke tangan Belanda dan pencetakan ORIPS terhenti. Pencetakan uang selanjutnya dilaksanakan di Bukit Tinggi yang pada masa agresi militer Belanda I masih dalam keadaan aman serta menjadi pusat pemerintahan Provinsi Sumatera setelah Pematang Siantar di kuasai Belanda. Emisi ORIPS Bukittinggi diterbitkan sebanyak 13 kali hingga tahun 1948 ditandatangani oleh Tengku Muhammad Hasan.

Di Bukit Tinggi ORIPS dicetak oleh Percetakan Tentara tahun 1947. Pengawasan dilakukan oleh Chaidir Hamid dan Nasrun A.S. Semula digunakan klise dari bahan tembaga, kemudian diganti dengan bahan kayu, karena bahan tembaga tidak dapat diperoleh lagi. Pembuat klise ORIPS adalah Usman Kagami. Sekitar tahun 1948 Percetakan ORIPS dialihkan di jalan Panorama Bukittinggi. Mesin-mesin cetak dikumpulkan dari berbagai percetakan swasta di Bukittinggi sejumlah sekitar 15 buah mesin leterpres degel tangan. Karyawan berjumlah sekitar 30 orang dan bekerja nonstop dalam 3 gilir setiap hari. Pencetakan ORIPS diawasi oleh Eni Karim, Sutan Bahrun Sjah dan Anwar Datuk Majo Basa nan Kuning (Team Penulis, 1984:32-33) 
Menurut Mr. Rasjid dalam ed.Mestika (1989:196) pada tahun 1947 dan 1948 percetakan ORIPS di Bukittinggi mencetak uang sebanyak satu koma lima ratus juta ORIPS (1.500 juta), yang dibagi bagikan sebanyak 500 juta untuk membayar hutang angkatan darat, 500 juta untuk membayar gaji pegawai sipil, dan 500 juta untuk pinjaman kepada petani biasa melalui madjelis Kredit Program.

Uang ORIPS yang dicetak di Bukittinggi berlaku untuk beberapa daerah di Provinsi Sumatera antara lain daerah Djambi, Riau, Atjeh, Sumatera Selatan, Sumatera Timur, Tapanuli, dan juga Sumatera Barat (Suwito,2020:131). Gencarnya aksi polisionil yang dilancarkan oleh Belanda dalam Agresi menyebabkan hubungan antara daerah-daerah Republik di Sumatera dengan ibu kota Provinsi di Bukittinggi menjadi terputus, termasuk distribusi ORIPS. Situasi inilah yang nantinya mendorong daerah- daerah lain di Pulau Sumatera, termasuk Sumatera Utara mengeluarkan ORIDA sendiri untuk dipakai sebagai alat pembayaran di daerah masing-masing berupa bon, bon sementara, spesial mandat atau mandat istimewa Percetakan ORIPS di Bukittinggi berakhir pada Agresi Militer Belanda II segala alat cetak dibumihanguskan oleh Belanda.

\section{Pencetakan ORIPS di Jambi}

Percetakan ORIPS kemudian dilanjutkan di Kota Jambi. Pada permulaan April 1949 diselenggarakan pemasangan kembali mesin cetak untuk mencetak ORIPS. Pada tahun 1947 sebelumnya Pemerintah Daerah Jambi memperoleh hak untuk mengeluarkan uang daerah. Percetakan "Soe Liong" dibeli oleh Pemerintah dan dijadikan Percetakan Negara. Ditunjuk sebagai Kepala Percetakan H.B. Yahya dan wakilnya Kamarni Thaib. Percetakan diletakkan dibawah pengawasan Jawatan Penerangan Daerah Jambi dengan M.L. Tobing sebagai Kepala Jawatan. Uang daerah yang pertama keluar bernama "Coupun Penukaran" terdiri dari pecahanpecahan 1 rupiah dan 21/2 rupiah, dengan bentuk sederhana sekali. Percetakan berproduksi terus sampai akhir tahun 1948 dengan hancurnya percetakan tersebut akibat serbuan tentara Belanda terhadap kota Jambi.

Dengan didudukinya Muara Tebo oleh Tentara Belanda pada tanggal 25 Mei 1949, percetakan ORIPS diungsikan ke Tanah Tumbuh dan dari sini dipindahkan 
ke Tanjung Belit, Rantau Ikil, 300 km dari kota Jambi. Semua alat percetakan diangkat kesana, secara dibongkar lepas-lepas. Pemasangan kembali mesin percetakan yang telah dibongkar tersebut dipercayakan kepada Kapten AURI Soerjono. Untuk menggerakkan motor digunakan bensin buatan dari bahan karet alam. Karena klise resmi dari PDRI belum diterima maka dibuat klise sementara dari kayu. Untuk mewarnai uang dibuat cat dari getah-getah jernang, tetapi hasilnya tidak baik maka diganti dengan tinta hitam. Karena warna hitam inilah maka ORIPS dijuluki ORIPS Hitam. Pecahan yang di cetak adalah 25 dan 50 rupiah atas nama Dewan Menteri Keuangan Jambi. Menteri Keuangan PDRI Mr. Lukman Hakim menyerahkan klise ke percetakan di Rantau Ikil untuk mencetak pecahan 10, 25, 50, dan 100 rupiah. Percetakan Negara PDRI di Rantau Ikil dipimpin oleh Komisaris Polisi Ahmad Bastari merangkap sebagai Sekretaris Dewan Pertahanan Daerah Jambi. Jumlah uang yang beredar selama percetakan ORIPS tersebut berjalan diperkirakan berjumlah Rp 42.750.000,-.

\section{Masa Berakhirnya ORIPS}

Pada saat Pemerintahan Republik Indonesia Serikat (RIS) terbentuk, Peredaran ORIPS perlahan-lahan diberhentikan. Hal ini disebabkan karena diwilayah Indonesia ternyata masih terdapat banyak macam uang yang beredar dan berlaku sebagai alat pembayaran dengan nilai tukar yang berbeda-beda. Berbagai jenis uang beredar di masyarakat antara lain: uang NICA yang tidak diakui pemerintah, uang DJB (De Javasche Bank) uang tersebut belum ditukarkan atau disimpan ke Bank yang ditentukan dalam UU No. 18 tahun 1946. ORI, dan puluhan jenis ORIDA termasuk ORIPS. Selain itu banyaknya ORI palsu semakin memperparah kesemrawutan peredaran mata uang yang diperlihatkan betapa tidak sehatnya ekonomi negara saat itu. (Darsono, 2017:306)

Untuk membenahi peredaran berbagai mata uang tersebut, pemerintah RIS kemudian mengeluarkan kebijakan penyeragaman jenis mata uang melalui penerbitan mata uang RIS (uang federal) dengan nilai Rp 5 dan 10 emisi Januari 1950. Keputusan penerbitan mata uang RIS tersebut juga juga diikuti dengan Maklumat Menteri Keuangan yang menetapkan penarikan ORI, ORIDA termasuk 
penarikan ORIPS, dan mata uang lainnya dari peredaran. Seluruh mata uang tersebut tidak berlaku sebagai alat pembayaran yang sah di daerah masing-masing sampai tanggal 1 Januari 1950. (parera, 2005:256)

\section{PENUTUP}

Alasan Provinsi Sumatera mencetak ORIPS karena perekonomian Indonesia di awal kemerdekaan sangat buruk akibat peninggalan dari penjajahan Jepang, yang diperparah dengan kedatangan tentara Sekutu dan NICA pada tanggal 4 Oktober 1945 di Tanjung Periok yang bertujuan untuk menguasai Indonesia kembali. Di awal kemerdekaan ada tiga mata uang yang beredar yaitu uang pendudukan Jepang atau Rupiah Jepang, Uang De Javasche Bank dan Uang NICA. Untuk mengatasi hal tersebut pemerintah RI membuat kebijakan dengan menerbitkan uang sendiri yang berlaku untuk seluruh wilayah Indonesia yang bernama Oeang Republik Indonesia (ORI). ORI diterbitkan pada 30 Oktober 1946 melalui pidato Muhammad Hatta pada 29 Oktober 1946. ORI hadir untuk menolak peredaran uang Jepang, De Javasche Bank, dan uang Nica. Namun, dalam peredaran ORI mengalami banyak kendala akibat dari aksi polisionil, dan blokade Belanda, kemudian geografis Indonesia yang berpulau-pulau sehingga ORI tidak tersebar secara merata keseluruh daerah-daerah termasuk di Pulau Sumatera. Oleh karena itu, pemerintah mengambil langkah agar kebutuhan dan perekonomian tiaptiap daerah tidak terhambat, maka melalui Peraturan Pemerintah No. 19/1947 tertanggal 26 Oktober 1947 Pemerintah Daerah tingkat Provinsi, Keresidenan, dan Kabupaten diberikan wewenang untuk menerbitkan Oeang Republik Indonesia Daerah (ORIDA). ORIDA adalah uang kertas atau tanda pembayaran yang sah yang berlaku secara terbatas didaerah tersebut. ORIDA pertama di pulau Sumatera bernama ORIPS (Oeang Republik Indonesia Provinsi Sumatera).

Proses pencetakan ORIPS dilaksanakan di Percetakan Negara II (Percetakan Deli) yang sebelumnya telah dipidahkan dari Kota Medan ke Kota Pematang Siantar. ORIPS dicetak dengan menggunakan kertas HVS/kertas buku. ORIPS yang bertanggal 31 Maret 1947 itu baru dapat dicetak pada bulan April 1947, adapun jenis pecahan yang dicetak adalah pecahan 1 Rupiah, 5 Rupiah, 10 Rupiah, 
dan 100 Rupiah. ORIPS mulai diedarkan pada tanggal 11 April 1947 sebagai tanda pembayaran yang sah di Sumatera. Pengeluaran ORIPS diatur maklumat Gubernur Sumatera no. 92/K.O tertanggal 8 April 1947.

Peran Oeang Republik Indonesia Provinsi Sumatera (ORIPS) dalam perjuangan Kemerdekaan Republik Indonesia yaitu Pencetakan ORIPS sangat banyak membantu masyarakat menolong perekonomian rakyat Sumatera, sebab masalah kesulitan keuangan sebagai alat pembayaran yang sah sudah dapat teratasi.

\section{DAFTAR REFERENSI}

Darsono Dkk (2017), Berjuang Dengan Uang Mempertahankan dan Memajukan Republik Indonesia: Semangat Juang Otoritas dan Masyarakat Sumatera Utara, Bank Indonesia: Jakarta.

Darsono Dkk (2016), Perjuangan Mendirikan Bank Sentral Republik Indonesia, Bank Indonesia: Jakarta.

Parera,D.J (Ed), (2005), Sejarah Bank Indonesia Periode I: 1945-1959 Bank Indonesia Pada Masa Perjuangan Kemerdekaan Indonesia. Bank Indonesia: Jakarta.

Soedarjdo, Nichlany, (1991), Banknotes And Coins From Indonesia 1945-1990, Yayasan Serangan Umum 1 Maret 1949 dan PERUM PERURI : Jakarta.

To, Oey Beng, (1991), Sejarah Kebijakan Moneter Indonesia Jilid I (1945-1958). Lembaga Pengembangan Perbankan Indonesiaan: Jakarta.

Team penyusun, (1988), Percetakan Uang RI Dari Masa ke Masa Cukilan Fakta dan Peristiwa peroide 1958-1971. Tanpa Penerbit dan Kota Terbit.

Sjamsuddin, Helius (2012), Metodologi Sejarah,Ombak: Yogyakarta.

Sulasman, (2014), Metode Penelitian Sejarah, Pustaka Setia: Bandung.

Amelia, Pidia, (2013). Gubsu Pertama dan Lahirnya Propinsi Sumatera Perjuangan Mr. SM. Amin mempertahankan Indonesia di Sumatera Utara 1945-1949.Unimed Press : Medan

Paeni, Mukhlis (Ed). 2009. Sejarah Kebudayaan Indonesia. Jakarta : PT Raja Grafindo Persada.

Kahin, Audrey, (1979). Perjuangan Kemerdekaan Sumatera Barat Dalam Revolusi Nasional Indonesia 1945-1950. Masyarakat Sejarawan Indonesia (MSI) 
Sjahnan, (1982). Dari Medan Area Kepedalaman dan Kembali Ke Kota Medan. Dinas Sejarah Kodam-II/BB

Nasution, A.H, (1970). Tentara Nasional Indonesia II. Seruling Masa Jakata.

Reid, Anthony, (2012). Sumatera Revolusi dan Elite Tradisional. Komunitas bambu.

Reid Anthony, (2011). Menuju Sejarah Sumatera Antara Indonesia dan Dunia. Yayasan Pustaka Obor Indonesia: Jakarta

TWH, Muhammad, (2004). Perjuangan Tiga Komponen Untuk Kemerdekaan. Yayasan Pelestarian Fakta Perjuangan Kemerdekaan RI: Medan

Uno, (2015). Oeang Nusantara. Bandung. Genera Publishing.

Zed, Mestika (Ed), (1979). Perjuangan Kemerdekaan Sumatera Barat dalam Revolusi Nasional Indonesia 1945-1950. Masyarakat Sejarawan Indonesia (MSI). Bukittinggi 